\title{
ENSINAR E APRENDER NA EDUCAÇÃO DO CAMPO: PROCESSOS HISTÓRICOS E PEDAGÓGICOS EM RELAÇÃO
}

\author{
Clésio Acilino Antonio* \\ MARIZETE LUCINI ${ }^{* *}$
}

\begin{abstract}
RESUMO: Neste texto resgatamos algumas questôes históricas da constituição de práticas educativas, que emergem das necessidades de diferentes grupos sociais em acessar a educação, privilegiando a educação popular como uma das matrizes pedagógicas constituintes da educação do campo. Esta é compreendida como uma prática social e política, que se efetiva nos processos de ensino e aprendizagem, e que nos propomos a discutir, na especificidade das escolas do campo. Essas práticas são tomadas como iniciativas construídas para superar modelos organizacionais e didáticos no currículo escolar. Para desenvolver esta discussão, após situarmos o campo do debate historicamente construído, estabelecemos um diálogo entre a relação do que identificamos nas práticas pedagógicas e o que é evidenciado como problemática na apropriação do conhecimento escolar. Esta reflexão incidirá na perspectiva de problematização sobre a efetivação de propostas alternativas na dinâmica curricular das escolas do campo.

Palavras-chave: Educação do Campo. Ensino. Currículo. Práticas Educativas.
\end{abstract}

TEACHING AND LEARNING IN RURAL EDUCATION: THE LINK BETWEEN HISTORICAL AND PEDAGOGICAL PROCESSES

ABSTRACT: This paper discusses the historical context of educational practices that emerge from the needs of different social groups

* Doutorando no Programa de Pós-Graduação em Educação da Universidade Federal do Rio Grande do Sul (Ufrgs) e professor dos cursos de Pedagogia e Pedagogia para Educadores do Campo da Universidade Estadual do Oeste do Paraná (unioeste). E-mail: clesioaa@yahoo.com.br

** Doutoranda no Programa de Pós-Graduação em Educação da Universidade Estadual de Campinas (UNICAMP) e professora dos cursos de Pedagogia e Pedagogia para Educadores do Campo da UNIOESTE. E-mail: zetelucini@hotmail.com 
Ensinar e aprender na educação do campo...

to have access to education. It points out how Popular Education is one of the pedagogical bases that constitute rural education. The latter is understood as a social and political practice present in all the teaching and learning processes and is here discussed within the particular frame of rural schools. Such practices come from initiatives built to improve didactical and organizational models in scholar curricula. To develop this discussion, after oulining the area to be debated and its historical construction, the text develops a dialogue between what is identified in pedagogical practices and what is thought to be problematic in school's knowledge acquisition. This analysis reflects on the problematization perspective of the activation of alternative proposals in the rural school's curricula dynamics.

Key words: Rural education. Teaching. Curriculum. Educational practices.

\section{A educação do campo: a constituição de um campo de discussão}

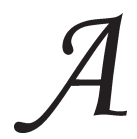

constituição histórica das práticas educativas emerge das necessidades de diferentes grupos sociais em acessar a educação. A perpetuação de traços coloniais na estrutura social brasileira, na composição dos governos e na administração do público tem fortes raízes rurais e patriarcais. A sobrevivência de traços coloniais na interpretação da realidade perpassa as relações históricas que conformam a estrutura fundiária brasileira. Atrelada a esta estrutura, a educação rural não é exceção nas determinações que, antes de representarem um instrumento de ruptura com a ordem estabelecida, sofrem processos de conformação em relação à estrutura social, cultural e econômica gestada no e para o país. Como afirma Leite (1999, p. 14):

A educação rural no Brasil, por motivos sócio-culturais, sempre foi relegada a planos inferiores e teve por retaguarda ideológica o elitismo acentuado do processo educacional aqui instalado pelos jesuítas e a interpretação político-ideológica da oligarquia agrária, conhecida popularmente na expressão: "gente da roça não carece de estudos. Isso é coisa de gente da cidade".

Delineia-se, assim, um imaginário de que, para viver na roça, não há necessidade de amplos conhecimentos socializados pela escola. Esta concepção de educação rural considerava que, para os trabalhadores do campo, não era importante a formação escolar já oferecida às 
elites brasileiras. As "escolinhas" criadas no meio rural, geralmente multisseriadas e isoladas, eram poucas e questionadas pelas forças hegemônicas da sociedade quanto a sua eficácia no ensino. Com o processo de urbanização crescente e o movimento de correntes migratórias, a educação rural começa a ser objeto de algumas preocupaçôes de alguns setores ligados à educação. Contudo, algumas iniciativas destas forças, de caráter assistencial e outras privadas, ${ }^{1}$ defendiam a necessidade de alguma formação para o trabalho agrícola. Também no âmbito público, algumas manifestaçôes se dirigiam a "clamar por uma educação de sentido prático e utilitário, e insistia-se na necessidade de escolas adaptadas à vida rural" (Calazans, 1993, p. 17).

Essa mesma autora afirma que se observam intenções do poder público de prover o meio rural de escolas já no século XIX. ${ }^{2}$ Porém, apenas a partir de 1930 é que os programas de escolarização do meio rural ganham corpo. Leite (1999) aponta o forte movimento migratório ocorrido no país no período 1910/1920 como desencadeador de um olhar mais atento para a educação rural, contexto em que surge o "ruralismo pedagógico", que pretendia uma escola integrada às condiçóes locais, objetivando assim fixar o homem no campo. ${ }^{3}$ A idéia de fixação do homem ao campo exaltava de forma romantizada uma educação voltada à "vocação" do país, entendida como agrária. Da terra deveria o homem retirar a sua felicidade e somente nela conquistaria o enriquecimento próprio e do grupo social do qual fazia parte (Calazans, 1993).

Esse ideal pedagógico se perpetuará por muitas décadas e podemos dizer que somos seus herdeiros, pois a idéia de uma educação vocacionada ressurge em todos os momentos que a educação do campo é discutida, embora os significados desta "vocação" possam diferir. O entendimento comumente realizado parece estar sedimentado na concepção de educcação rural, como aquela que, além de ensinar a ler, contar e escrever, pode incluir técnicas agrícolas em seu currículo e assim estará contribuindo para fixar o homem no campo. ${ }^{4}$

A apropriação da discussão da problemática da educação rural, na perspectiva dos sujeitos que nela atuam e sofrem as ausências de políticas que as contemplem, dar-se-á no bojo do movimento de educação popular, que compreendemos com Paludo (2001, p. 82) "como uma prática educativa que se propõe a ser diferenciada, isto é, compromissada com os interesses e a emancipação das classes subalternas". 
Ensinar e aprender na educação do campo...

A autora situa a emergência dessa concepção antes da Proclamação da República, por ocasião dos movimentos operários que se formam e atuam naquele período, e aponta a fundação de bibliotecas populares e escolas operárias para crianças e adultos, mantidas pelas entidades operárias e, também, por recursos buscados no poder público. Podemos então situar essas iniciativas operárias como as precursoras de uma educação popular, considerando-se que nessas experiências são debatidas questôes pedagógicas, como o que ensinar e como educar, com a explicitação da educação como atividade inserida nas lutas sociais. A preocupação dos socialistas do período, em alinhar o conhecimento científico com a prática do trabalhador, também merece destaque, pois funda um dos pilares do que se desenvolverá como Educação Popular no Brasil, inaugurando uma postura política, na defesa de uma educação como prática social que será assumida pelos movimentos sociais, em diferentes momentos de nossa história (Paludo, 2001, p. 82-83).

As experiências anarquistas e anarco-sindicalistas no Brasil ocorrem com maior intensidade no início do século XX e propóem uma educação para a liberdade. Para tanto, entende que o Estado, a Igreja e o Capital necessitam ser combatidos, desenvolvendo "uma prática pedagógica intimamente associada às suas propostas de como deveria ser a sociedade: autogerida e livre" (idem, ibid., p. 83). Todas as iniciativas libertárias foram reprimidas e, em 1919, suas escolas são fechadas.

Durante o Estado Novo, teremos um silenciamento de muitas lutas, tal qual o que calou sobre o fechamento das escolas anarquistas. A partir da década de 1950-1960, porém, emergem e se consolidam movimentos ligados às mais variadas instâncias sociais, como os Movimentos de Cultura Popular (МСР), do qual participou Paulo Freire, o Movimento de Educação de Base (MEB), criado pela Confederação Nacional dos Bispos do Brasil (CNBB), e os Centros Populares de Cultura (CPC), criados pela União Nacional dos Estudantes (UNE). É nessa emergência da educação popular nos anos de 1960 que o educador Paulo Freire demarca uma proposta de educação libertadora.

\section{A educação popular, a educação libertadora e a educação do campo}

A educação popular, como composição teórico-prática sobre a situação educacional do país, se insere nos movimentos sociais que tencionam 
o Estado. Ao mesmo tempo em que se torna uma prática propositiva, esta composição busca compreender questôes educacionais a partir de um quadro político-democrático, no qual se manifestam as lutas pelas transformações sociais a partir da educação, nas dimensôes de luta pela cidadania em sua relação à qualidade de vida (Nogueira, 1999). O que é possível esperar desta relação de contradições é a transformação, visto que torna a educação inovadora, apostando que é possível transformar a realidade, a dominação e a ação do dominador (Freire \& Nogueira, 2002).

Com efeito, a pedagogia que Freire propõe encontra ressonância nos movimentos sociais, pois, como afirma Paludo (2001, p. 91), "É nos anos de 1960, com Paulo Freire, que no Brasil se tem, pela primeira vez, de forma consistente, uma pedagogia anunciada das classes populares". 5 Proposta que adentra o campo popular porque contempla esses grupos sociais, partindo do vivido para propor uma transformação.

A possibilidade de pensar a educação a partir das classes trabalhadoras, sob o princípio de uma educação que liberta e concebe a vida humana para além das desigualdades, por meio de um processo dialógico, tornou-se uma referência para pensar a educação popular. A inserção da proposta de Freire nos anos de 1960 sobreviverá à intensa repressão sofrida pelo povo brasileiro no período da ditadura militar, até porque as Comunidades Eclesiais de Base (CEB), organizadas e mantidas pelo setor progressista da Igreja Católica, continuam a existir e a atuar, como nos diz Frei Beto (2006, p. 196), ao escrever sobre o poder popular na América Latina: "No caso brasileiro, na falta de espaços orgânicos de rearticulação política, devido à severa repressão militar, um segmento importante dessa nova esquerda buscou a esfera pastoral das Comunidades Eclesiais de Base como meio de inserção no universo popular”.

A continuidade do movimento para uma educação que respondesse às necessidades das classes trabalhadoras, de reconhecer-se na proposta educativa, possibilita que a proposta de Freire seja tomada nas mãos pelos educadores populares, e nessa apropriação ela se transforma, incorpora outros elementos, vive o que podemos nominar como um fazer-se pedagógico, principalmente a partir do que Frei Beto denomina como "mudança de lugar social", ou seja, se anteriormente a educação popular estava vinculada ao movimento sindical, agora ela 
Ensinar e aprender na educação do campo...

vivenciará outro tipo de relação, já que acolhida e assumida no espaço das CeB. Para Frei Beto, essa mudança é de caráter epistêmico.

$\mathrm{Na}$ possibilidade de um ressurgimento da organização popular, fenômeno que ocorre em toda a América Latina na década de 1970, com a contribuição do setor progressista da Igreja Católica, adepto da Teologia da Libertação, podemos observar o nascimento, ou ressurgimento, de movimentos sociais compostos por sujeitos sociais fortalecidos em sua consciência política, que desencadearão ações como os acampamentos zapatistas no México e as ocupações dos sem-terra no Brasil (Frei Beto, 2006, p. 196).

Contudo, parece que as características desses "novos" movimentos apresentam elementos diferenciados, como sua organicidade, instâncias decisórias, desvinculação de instituições reguladoras e normatizadoras. Possivelmente, essa "renovada" forma de estar em movimento é decorrente do processo formativo em que esses movimentos são construídos, em que a dialogicidade, proposta por Freire, parece ser uma referência.

No Brasil, o Movimento dos Trabalhadores Rurais Sem-Terra (MST) tornar-se-á, a partir da década de 1980, o mais combativo e forte movimento social do campo. Um dos seus eixos de proposição e ação é o da educação, que se constituiu como uma necessidade no processo de construção e reconstrução do Movimento. Como aponta Arroyo, na apresentação do livro de Caldart (2000), a relação que o MST estabelece com a educação remete a outros momentos da história. Vejamos:

Penso em um dos capítulos tão fecundos na história da educação latinoamericana: a educação popular e o pensamento de Paulo Freire. Eles nasceram colados à terra e foram cultivados em contato estreito com os camponeses, com suas redes de socialização, de reinvenção da vida e da cultura. Nasceram percebendo que o povo do campo tem também seu saber, seus mestres e sua sabedoria. (Arroyo, 2000, p. 14)

Assim, o pensamento de Freire, por estar enraizado na profunda indignação dos educadores, diante dos processos desumanizadores vividos pelos camponeses, encontra-se com o sonho de libertação dos sem-terra que, organizados, se tornam os Sem-Terra, e um dos alicerces da Pedagogia do Movimento situa-se na Pedagogia Libertadora proposta por Freire. ${ }^{6}$ 
A educação desenvolvida nos meios rurais torna-se objeto de discussão dos sujeitos que a compõem, os educadores e camponeses, diferentemente de outros momentos, em que a educação rural era objeto de discussão dissociada dos sujeitos sociais que nela atuam. Até então denominada como educação rural, é (re)nominada como educação do campo, pois, como entendem os sujeitos sociais deste movimento:

Decidimos utilizar a expressão campo e não mais a usual meio rural, com o objetivo de incluir no processo (...) uma reflexão sobre o sentido atual do trabalho camponês e das lutas sociais e culturais que hoje tentam garantir a sobrevivência deste trabalho. (Fernandes, Cerioli \& Caldart, 2004, p. 25)

Esta denominação compreende uma nova concepção do rural, não mais como lugar de atraso, mas de produção da vida em seus mais variados aspectos: culturais, sociais, econômicos e políticos. Compreende também diferentes povos do campo, como os indígenas e quilombolas que, na lógica da sociedade capitalista, não são mencionados por diferirem das práticas capitalistas de produção, como nos informa o documento da I Conferência Nacional Por uma Educação Básica do Campo: ${ }^{7}$

(...) quando discutimos a educação do campo estamos tratando da educação que se volta ao conjunto dos trabalhadores e das trabalhadoras do campo, sejam os camponeses, incluindo os quilombolas, sejam as nações indígenas, sejam os diversos tipos de assalariados vinculados à vida e ao trabalho no meio rural. (Idem, ibid.).

Identificados pelas problemáticas vividas, os povos do campo encontram na Pedagogia Libertadora um dos ancoradouros para a discussão dos processos de exclusão e empobrecimento crescente dos trabalhadores. Processos que adentram a escola, nos seus aspectos organizacionais e didáticos do currículo escolar.

Com efeito, ao definir que, no processo de transformação social, a escola é mais do que escola, lê-se um primeiro indicativo sobre a necessidade de transformar também a escola. Acompanhemos a reflexão de uma professora acerca da função da escola no processo de transformação social: 
Ensinar e aprender na educação do campo...

(...) não foi por acaso que a gente se tornou sem terra, o que é que aconteceu, o que é que tem por trás de a gente ter se tornado sem terra pessoas, (...) não dá para usar essa expressão, pessoas excluídas da sociedade, mas é o que aconteceu se a gente se tornou sem terra, alguma coisa tem de errado. (...) na questão da gente ter se tornado sem terra, tem alguma (...) alguma coisa por trás, e pode até ter escola, não vou afirmar assim, nem posso, nem devo, é uma reflexão que estou fazendo agora, eu acho que a escola onde a gente foi, a escola não preparou a gente para enfrentar a vida (...) e a gente faz essa reflexão também com as crianças, o que é que é se preparar para a vida? O que é que é ser alguém na vida? E a criança tem muito dessa fantasia de ser médico, advogado, enfim, eu posso ser médico, ser advogado, mas desde que conte, dá retorno para essa classe trabalhadora (...) e se a gente conseguir trabalhar com a criança assim, no sentido dela voltar, dar um retorno de luta e amor à terra. (Entrevista concedida em 31 ago. 2005).

Preparar para a vida, portanto, perpassa também o processo formativo desenvolvido na escola e ultrapassa um sentido individualista, em que caberia ao sujeito estabelecer a relação de sua formação com a realidade social e econômica. Esse vínculo adquire, no âmbito da educação popular, um caráter orgânico entre a formação escolar e inserção social dos sujeitos, que necessita ser explicitado no próprio processo das práticas educativas desenvolvidas.

A educação popular é, portanto, uma prática política, constituindo-se num tencionamento, para que a realidade se transforme a partir de propostas populares em educação. Como prática educativa coletiva das classes populares, a educação popular é um campo de luta social, em que nos envolvemos em um movimento permanente, buscando a transformação de um quadro histórico que a educação do povo, trabalhadores urbanos e do campo, enfrenta, por estar diferentemente colocada em certos contextos de nossa formação social, em contradição com a necessidade social e econômica (Paiva, 1987).

Nosso olhar, situado na relação histórica educação popular/educação libertadora/educação do campo, volta-se para o que anunciamos como um diálogo entre a relação do que identificamos nas práticas pedagógicas e o que é evidenciado como problemática na apropriação do conhecimento escolar, como possibilidade de compreender a operacionalização e efetivação dos condicionantes históricos no campo das práticas curriculares. Para tanto, tomemos a prática pedagógica que tem 
uma referência nos Temas Geradores, proposta Freireana, para a continuidade deste diálogo.

\section{A prática pedagógica libertadora}

Discutir a prática da educação escolar, a partir de um recorte dos condicionantes históricos da educação popular/educação libertadora/ educação do campo, possibilita-nos avaliar as relações pedagógicas que são construídas e permeadas por uma tradição educacional, no sentido de questionar e analisar "uma série de prioridades e hipóteses que foram herdadas e deveriam estar no centro do nosso esforço para entender a escolarização na teoria e operacionalizá-la na prática" (Goodson, 2001, p. 28). A tradição "bancária", para situarmos uma referência teórico-prática crítica à escolarização, torna-se aqui um âmbito de reflexão sobre proposições construídas por Freire, provocando muitos debates e proposiçôes educacionais nas escolas do campo, principalmente àquelas vinculadas ao MST, que adotam a Pedagogia do Movimento como referência à superação da prática pedagógica verticalizada, negadora da prática educativa dialógica: "Educa-se para arquivar o que se deposita" (Freire, 1979); "arquivados, porque, fora da busca, fora da práxis, os homens não podem ser” (Idem, 1987). Neste sentido, a proximidade com as questôes de natureza teórico-prática presentes na ação pedagógica vem se tornando uma possibilidade de compreensão de um espaço de "recriação" e "reelaboração" como prática, a partir da totalidade educativa.

Ao organizar o trabalho pedagógico por Temas Geradores capilariza-se, predominante como orientação às práticas das escolas situadas nos princípios político-pedagógicos de alguns sistemas municipais e estaduais de educação (Freire, 1991; Barreto, 1998; Saul, 1998), do Movimento dos Trabalhadores Sem-Terra (Caderno de Educação, n. 9, 1999), e iniciativas de programas de formação de professores do campo (Cadernos Pedagógicos, 2000; Antonio \& Osbi, 2004; Lucini, 2005), como outras que buscam superar os limites do modo como o currículo escolar se organiza e se constitui historicamente na escola, pelas divisões das tarefas entre os educadores, visto a compartimentalização dos conhecimentos, como as habilidades em matérias ensinadas nas escolas (Enguita, 1989). 
Ensinar e aprender na educação do campo...

A opção pela organização curricular a partir do Tema Gerador nasce e se desenvolve na reflexão experienciada pelos movimentos sociais, que compreendem a educação e a escola como parte de um projeto de desenvolvimento e o próprio movimento como sujeito educativo. No entanto, os sistemas municipais e estaduais de ensino, ao orientar a formação continuada de professores do campo, optando pela organização curricular a partir dos Temas Geradores tendem a efetivar essa proposta de forma diferenciada, porque dissociada de uma opção política de transformação social orgânica, correndo-se o risco desta opção tornar-se apenas uma forma diferenciada de organizar o currículo, não correspondendo que a educação das classes trabalhadoras seja tomada nas mãos pelos sujeitos que a compõem, os trabalhadores.

As opções que buscam reorganizar os currículos das escolas do campo, em seus aspectos de participação coletiva não apenas restritas ao planejamento curricular, mas também aos elementos didáticometodológicos, são dimensóes sócio-educativas situadas na dinâmica permanente da decisão do ensino e da aprendizagem. Portanto, são opçôes em que a comunidade, os educadores, educandos e escolas tomam como mobilizadoras sobre suas próprias construçōes curriculares, como um "processo em constante construção, que se faz e se refaz (...) como um caminho onde a participação dos actores que interagem no processo educativo é condição da sua construção" (Saul, 1998, p. 155).

Observemos como esta proposta se gesta no processo de escolha do tema gerador, importando nesse trabalho o processo em que os diversos sujeitos estão envolvidos:

(...) o tema gerador é parte de um problema da comunidade, ou de uma coisa bonita, de uma motivação, que no final a gente possa desenvolver na escola (...) na verdade a gente faz uma pré-discussão na comissão de educação e a gente levanta possíveis temas que poderiam ser trabalhados (...) o que deu mais certo é a comissão fazer a discussão e enviar para o núcleo. A gente envia os temas, e o núcleo discute e aí em assembléia fala o que os núcleos aprovaram e vai para a aprovação. Daí se aprova. (...) a assembléia decide o tema e volta para a comissão, a comissão de educação já bota no plano anual, o planejamento volta para o núcleo de famílias para estudar, enfim, contemplar ou sugerir mudanças, aí depois que volta o planejamento, daí sim, as aulas ficam a cargo do educador. (Entrevista com educadora concedida em 23 ago. 2005) 
Observa-se nesta prática a preocupação com a discussão do tema pela comunidade, não cabendo aos educadores a decisão preponderante, mas à instância coletiva, o que, de antemão, implica a compreensão de que a temática a ser estudada deve estar organicamente vinculada às problemáticas vividas pela comunidade. Os temas aprovados em assembléias recebem, posteriormente, ao retornarem para a comissão de educação, um tratamento de organização pedagógica, pelo qual são definidas as questões norteadoras. Estas são compreendidas como uma parte do tema gerador. É propriamente a organização curricular que é desencadeada a partir do tema gerador, pelo qual os conteúdos e os tempos pedagógicos são definidos. As aulas ficam a cargo do educador. Portanto, para que esse processo seja efetivado, o educador é agente ativo, participando de todas as instâncias de discussão, não como definidor, mas como um integrante fundamental.

Remetermo-nos à discussão de como as opções de organização do ensino estão arraigadas a uma concepção de educação libertadora nos faz identificar como esta concepção está implicada na seleção dos próprios conhecimentos ou conteúdos escolares. Nesta concepção, a prática dialógica, a qual inaugura a relação pedagógica entre educadoreducando-comunidade, como antecipadora do encontro ou da situação problematizadora da educação, que vai situar a busca pelo conteúdo programático, ou o conteúdo do diálogo, é uma opção curricular que não parte de um programa fechado, pré-estabelecido numa organização de pré-requisitos, na qual os conhecimentos e valores se manifestam com "existência autônoma", mas que "dependem, para realizarse, de humanos que os elaborem, atribuindo-lhes significados e dando-lhes suporte de manifestação" (Cortella, 2004, p. 47). Neste sentido, nesta concepção de educação como prática de liberdade, importa que:

(...) a sua dialogicidade comece, não quando o educador-educando se encontra com os educandos-educadores em uma situação pedagógica, mas antes, quando aquele se pergunta em torno de que vai dialogar com estes. Essa inquietação em torno do conteúdo do diálogo é a inquietação em torno do conteúdo programático da educação. (Freire, 1987, p. 83)

Trata-se de uma concepção pedagógica que apresenta uma direção de caráter histórico-social à inserção dos sujeitos e suas realidades 
Ensinar e aprender na educação do campo...

dinâmicas, o que se relaciona diretamente às opções autônomas que as escolas constroem na efetivação de seus currículos.

Ao decidir pela seleção, forma de organização e distribuição dos conhecimentos, as comunidades definem sua própria caminhada de opção teórico-metodológica transformadora, envolvendo suas discussões nas opções de concepção de homem, de sociedade e de educação. Definiçãao que é uma opção política, compreendida como possível e necessária de se materializar na seleção do que e como ensinar, pela comunidade e pela escola, como forma de contribuir na transformação de uma realidade social, a partir da práxis dialógica.

Na educação do Movimento Sem-Terra, discutiu-se até que ponto os filhos dos Sem-Terra deveriam participar da escola que nos tornou semterra, excluídos da sociedade. Essa escola não nos preparou para enfrentar a vida. O que nós sabíamos é que queríamos uma escola diferente. Essa idéia de escola foi sendo construída a partir de educadores como Paulo Freire, Pistrack e Makarenko. (...) O INCRA construiu a nossa escola, mas não se tinha claro que era tão difícil assim. (...). Para a secretaria da educação o método da palavra geradora era inconcebível, mas fomos fazendo do nosso jeito. (Depoimento da comissão de educação concedido em 14 jun. 2005)

Nesta experiência específica, podemos inferir que os sujeitos envolvidos no processo compreendem que a escola que desejam implica uma opção política, e, tomada essa posição, constroem coletivamente esta escola no diálogo com educadores que irão subsidiar, teóricometodologicamente, essa opção. A construção de uma "escola diferente" passa necessariamente pela construção coletiva, na qual a dialogicidade é o cimento que permitirá que ela seja edificada.

A conjunção entre o sujeito que educa-aprende e o sujeito que aprende-educa, considerando-se o próprio movimento social como sujeito que também educa, situa-os numa prática compartilhada por processos de emancipação que devem ser colocados em ação coletivamente e em interaçóes culturais cada vez menos assimétricas. Por isso mesmo que esta prática implica:

(...) que o acercamento às massas populares se faça, não para levar-lhes uma mensagem "salvadora", em forma de conteúdo a ser depositado, mas, para, em diálogo com elas, conhecer não só a objetividade em que 
estão, mas a consciência que tenham desta objetividade; os vários níveis de percepção de si mesmos e do mundo em que e com que estão. (Freire, 1987 , p. 86)

Fica evidente que esta razão social e pedagógica de construir a prática educativa libertadora entra em contradição com a organização do currículo escolar já estabelecido e engendrado numa dinâmica escolar que administra e domina os conhecimentos, como elementos pré-estruturados, como fatos estéreis. Nesta concepção curricular, o conhecimento está fortemente sedimentado por uma tradição técnico-instrumental que, ao ser naturalizada como dominante, exclui a dimensão social e concreta do conhecimento, para apenas ser acumulado e categorizado, como conhecimento dado, tendo em si mesmo o seu valor, que se autonomiza "em relação às bases históricas que o tornaram possível e lhe dão sentido" (Pedra, 1997, p. 58). Nesta tradição, o conhecimento é apresentado como externo e imposto aos sujeitos, sem possibilidade de questionamentos e análises compartilhadas, "divorciado do significado humano e da troca intersubjetiva (...), separado do processo de geração de nosso próprio conjunto de significados, um processo que envolve uma relação interpretativa entre conhecer e conhecido" (Giroux, 1997, p. 45).

É nesta dinâmica escolar de ruptura com o estabelecido que o trabalho com os Temas Geradores vem se constituindo em desafio nas práticas dos educadores nas escolas do campo. $\mathrm{Na}$ prática educativa com estes Temas, principalmente em escolas que têm nesta opção uma decisão do corpo docente ou do sistema, os educadores têm em seu horizonte a permanente e complexa responsabilidade de decidir, como corpo docente, sobre a organização do trabalho pedagógico. Na complexidade vivenciada, um dos elementos enfrentados diz respeito àquela anterior e complexa trama de uma tradição curricular, na qual o agir a partir da necessidade de ensinar conteúdos estéreis já selecionados, previstos, seqüenciados e decididos para o processo sócio-educativo e formativo, situados numa prática educativa, deixa de tomar o movimento real e situacional dos sujeitos envolvidos.

\section{Considerações finais}

A associação entre as concepções tradicionais de organizar e classificar os conhecimentos escolares, ambiguamente presentes, com uma 
Ensinar e aprender na educação do campo...

concepção de prática pedagógica fundada nos referenciais históricos da educação popular revela algumas problemáticas vivenciadas em sua aplicabilidade. Indicamos algumas questôes que observamos no campo das práticas educativas com Temas Geradores, para nossa reflexão e, talvez, como viabilidade de reatualizarmos nossas ações no âmbito da educação do campo, revendo quais os laços que ainda não chegamos a romper com uma tradição escolar que se impõe por sua força histórica constituinte.

A prática complexa de planejamento curricular, orientada pela opção de organização curricular a partir dos Temas Geradores, muitas vezes, pode conceber, por exemplo, um tema, definido de modo amplo para toda a escola, deslocado de seu sentido mais particular das relaçôes homem-mundo. Este efeito ao trabalho pedagógico é resultado influente da própria dinâmica escolar, em que os agrupamentos de educandos são constituídos pela lógica de escolarização moderna, seqüenciada em séries-idades. Imprimir sentidos ao trabalho pedagógico com certos Temas Geradores, de modo logístico a toda a escola, vem apresentando questóes didático-metodológicas a serem resolvidas, quando os próprios Temas tendem a ser isolados das realidades dos seres humanos, em suas situações de existencialidade (Freire, 1987). Essa relação deve ser entendida nas relações particulares de como os seres humanos estão no mundo, em seus níveis de compreensão, suas visões, seus valores, para que no ensino ocorra a análise e reflexão da prática social a ser melhor compreendida e transformada.

Para Freire (1987, p. 102), “(...) toda investigação temática, na concepção problematizadora da educação, se torna momento de um mesmo processo", dificilmente constituído quando fazemos levantamentos metodológicos simplificadores.

Um dos problemas importantes para debatermos refere-se a como estes temas são selecionados e hierarquizados para serem trabalhados, como uma preocupação permanente dos professores que colocam a referência a um conhecimento a ser seguido uniformemente em cada momento da formação escolar. De modo controverso, as seleções de conhecimentos escolares, partindo dos conteúdos já tradicionalmente colocados como fundamentais para a aprendizagem das crianças, não recebem, muitas vezes, a devida atenção sobre sua concepção, que se tornou um amplo quadro de referências para os professores, como os 
conteúdos das disciplinas no currículo. Neste sentido, a organização disciplinar pode estar sendo debatida e tratada de outro modo, mas, possivelmente, a origem dos conhecimentos nas áreas ou disciplinas escolares está deixando de ser questionada em suas mais particulares representações sobre o conhecido. Se o suporte do conhecimento escolar, em suas diversas composiçôes epistemológicas, como áreas ou disciplinas escolares, imprime sentidos importantes aos aspectos mais sistemáticos do fenômeno social trabalhado, significado em Temas Geradores, estes devem cumprir sua própria razão cognoscitiva de apropriação pelos educandos. Um suporte que não pode ser desprendido de sua origem teórico-metodológica, de como está apresentado, quando muito consultado por materiais didáticos utilizados pelos educadores.

Outra questão significativa, já apontada acima, mas que julgamos fundamental nas reflexōes finais, refere-se à relação educador-educando-escola-comunidade. Freqüentemente, observa-se que, quando a opção por organizar o currículo por Temas Geradores é pontual e não há participação da comunidade, os elementos externos pressionam a escola e o educador, questionando a validade dos conhecimentos e das práticas pedagógicas desenvolvidas. Isso se funda numa concepção escolarizada de educação, e também numa concepção de que a escola é uma instituição desvinculada das práticas sociais. As pressōes sofridas pela escola e pelos educadores, quando não arraigadas num processo que visa à transformação da realidade vivida, podem constituir-se em fator de rompimento com a possibilidade de avançar nessa proposta, ou então mascará-la, enquadrando-a numa outra lógica, que não aquela que funda o trabalho com Temas Geradores, qual seja, a da tomada da educação pelos trabalhadores, um processo de um constante refazer-se.

Nestas práticas são enfrentados os conflitos político-ideológicos das condições materiais, condições espaço-temporais etc. Ao mesmo tempo, não são poucas as questôes de natureza de concepção educativa que os educadores e as escolas encontram pela frente, principalmente quando os Temas Geradores são trabalhados nos anos finais do ensino fundamental, nos quais as disciplinas escolares regem uma organização mais definida ou rígida à distribuição dos conhecimentos numa prática para diversos professores, em certos grupos de educandos. Uma questão não tão problemática nos anos iniciais deste nível de ensino, enquanto dimensão da regência ou coordenação do trabalho pedagógico, 
Ensinar e aprender na educação do campo...

pelo fato de que este está sob a direção da prática unidocente, um educador, organizada por ele mesmo.

As reflexões possíveis diante das dificuldades na apropriação de uma prática pedagógica fundada na concepção de uma educação libertadora, que, juntamente com outras práticas sociais e políticas, viabilize uma transformação social, nos impelem a afirmar que necessitamos, como educadores, continuar a reinventar nossas práticas pedagógicas, problematizando-as, para que, assim, se tornem, elas também, temáticas em processo de conhecimento.

Processos de conhecimento que sempre estão historicamente situados, que são engendrados em movimentos que podem propor rupturas ou não com as formas de educar. Adentrando o campo do currículo e, nele, o das práticas pedagógicas, a íntima relação entre a sociedade que temos e a que queremos pode ser potencializada a realizar as transformações pelas mãos dos trabalhadores ou, então, permitir que elas continuem sendo determinadas por agentes externos, desvinculados das problemáticas vividas pelos povos do campo.

A história da educação popular, uma das geradoras dos fundamentos da educação do campo, como vimos anteriormente, possibilita-nos compreender que os anseios populares de transformar a sociedade em que vivemos encontraram nos Temas Geradores uma das formas de problematizar essa realidade, mas também nos mostra que os processos históricos estão sempre se fazendo, e, como agentes deste processo histórico, necessitamos nos situar em constante refazer-se. Essa dinamicidade processual constitui-se em matéria de reflexão, que nos permite sempre reelaborar nossas práticas pedagógicas no sentido de uma educação necessária à libertação e nos remete ao desafio constante de reiventar as formas como as produzimos, o que significa refletirmos sobre a complexidade em que nossas práticas educativas estão imersas.

Recebido em outubro de 2006 e aprovado em março de 2007.

\section{Notas}

1. Para mais informações sobre a origem destas ações desenvolvidas no Brasil, ver Schueler (2000).

2. O ensino público no Brasil é assumido pelo Estado, a partir da expulsão dos jesuítas, em 1759, pelo então ministro de Estado em Portugal, Marquês de Pombal. "Em ambos os 
países, ainda que a mão de obra para o ensino continuasse a ser aquela formada pelos jesuítas, nasceu o que, de certo modo, podemos chamar de ensino público, ou seja, um ensino mantido pelo Estado e voltado para a cidadania enquanto nação que se articularia ao Estado, e não mais um ensino atrelado a uma ordem religiosa o que de fato - como denunciou Pombal - estava tendo preponderância sobre o Estado" (Ghirardelli Jr., 2001, p. 15).

3. Uma das discussões sobre o ruralismo pedagógico pode ser encontrada em Bezerra Neto (2003).

4. Importa mencionar que a defesa de uma escola rural "voltada a uma vocação" agrária, como mecanismo de fixação do homem no campo, insere-se na lógica do liberalismo, que mantém desatreladas as instâncias educação e desenvolvimento como um processo coletivo. Para a doutrina liberal, as transformações na educação são suficientes, já que compreende que a ascensão social dos indivíduos varia de acordo com as aptidóes de cada um, ou seja, a escola deve oferecer igualdade de condições de acesso, mas isso não contempla as condições materiais de acesso à escola, apenas é entendida como oferecimento de vagas para todos. Para estudo da relação liberalismo e educação, ver Cunha (1991).

5. Paludo (2001, p. 91) aponta em sua pesquisa que, "Segundo alguns estudiosos, a Pedagogia Libertadora de Paulo Freire emergiu nutrindo-se da ideologia nacional-desenvolvimentista do ISEB, do pensamento progressista da Igreja Católica, dos princípios da Pedagogia Nova e das práticas vividas no interior dos movimentos de cultura popular e de alfabetização de adultos".

6. Outros educadores também contribuem na construção da proposta educativa do MST, como Pistrack, Makarenko e outros, mas, neste texto, nos deteremos nas contribuições de Freire para análise de práticas pedagógicas.

7. A I Conferência Nacional "Por uma Educação Básica do Campo" aconteceu em Luziânia, Goiás, de 27 a 31 de julho de 1998, e teve como principal objetivo "ajudar a recolocar o rural e a educação que a ele se vincula, na agenda política do país” (Fernandes, Cerioli \& Caldart, 2004, p. 22).

\section{Referências bibliográficas}

ANTONIO, C.A.; OSBI, R.C.S. O currículo das escolas do campo: reflexões sobre experiências com temas geradores. In: ANTONIO, C.A. et al. (Org.). Identidade profissional, conhecimento e práticas educativas. Francisco Beltrão: UNIOESTE, 2004. p. 138-148.

ARROYO, M.G. Apresentação. In: Caldart, R.S. Pedagogia do Movimento Sem-Terra: escola é mais do que escola. Petrópolis: Vozes, 2000 .

BARRETO, E.S.S. (Org.). Os curriculos do ensino fundamental para as escolas brasileiras. Campinas: Autores Associados; São Paulo: Fundação Carlos Chagas, 1998.

Cad. Cedes, Campinas, vol. 27, n. 72, p. 177-195, maio/ago. 2007

Disponível em <http://www.cedes.unicamp.br> 
Ensinar e aprender na educação do campo...

BETTO, F. A mosca azul: reflexões sobre o poder. Rio de Janeiro: Rocco, 2006.

BEZERRA NETO, L. Avanços e retrocessos na educação rural no Brasil. 2003. 221f. Tese (Doutorado) - Faculdade de Educação, Universidade Estadual de Campinas, Campinas.

CALAZANS, M.J.C. Para compreender a educação do Estado no meio rural: traços de uma trajetória. In: Therrien, J.; Damasceno, M.N. (Org.). Educação e escola no campo. Campinas: Papirus, 1993.

CALDART, R.S. A escola do campo em movimento. In: Arroyo, M.G.; Caldart, R.; Molina, C.M. (Org). Por uma educação do campo. Petrópolis: Vozes, 2004.

CALDART, R.S. Pedagogia do Movimento Sem-Terra: escola é mais do que escola. Petrópolis: Vozes, 2000.

COTELLA, M. S. A escola e o conhecimento: fundamentos epistemológicos e políticos. São Paulo: Cortez, 2004.

CUNHA, L.A. Educação e desenvolvimento social no Brasil. Rio de Janeiro: Francisco Alves, 1991.

ENGUITA, M.F. A face oculta da escola. Porto Alegre: Artes Médicas, 1989.

ESCOLA Pública do Campo: o conhecimento enraizado na vida. Cadernos Pedagógicos - Serie Formação de professores, Francisco Beltrão, n. 1, dez. 2000.

FORQUIN, J. Escola e cultura: as bases sociais e epistemológicas do conhecimento escolar. Porto Alegre: Artes Médicas, 1993.

FREIRE, P. Educação na cidade. São Paulo: Cortez, 1991.

FREIRE, P. Pedagogia do oprimido. 17. ed. Rio de Janeiro: Paz \& Terra, 1987.

FREIRE, P.; NOGUEIRA, A. Que fazer: teoria e prática em educação popular. Petrópolis: Vozes, 2002.

GIROUX, H.A. Os professores como intelectuais: rumo a uma pedagogia crítica da aprendizagem. Porto Alegre: Artes Médicas, 1997. 
GOODSON, I.F. Currículo: teoria e história. Petrópolis: Vozes, 1995. LEITE, S.C. Escola rural: urbanização e políticas educacionais. São Paulo: Cortez, 1999.

LUCINI, M. A formação de professores do campo: necessidades e possibilidades. In: PinheIro, A.S. et al. (Org.). Educação, currículo, ensino e formação de professores. Francisco Beltrão: UnIOESTE, 2005.

PAIVA, V.P. Educação popular e educação de adultos. São Paulo: Loyola, 1987.

PALUDO, C. Educação popular em busca de alternativas: uma leitura desde o campo democrático e popular. Porto Alegre: Tomo; Camp, 2001 .

PEDRA, J. A. Currículo, conhecimento e suas representaçôes. Campinas: Papirus, 1997.

SAUL, A.M. A construção do currículo na teoria e prática de Paulo Freire. In: Apple, M.W.; NóvoA, A. (Org.). Paulo Freire: política e pedagogia. Porto, Porto, 1998. p. 151-65.

SCHUELER, A.F.M. A “infância desamparada” no asilo agrícola de Santa Isabel: instrução rural e infantil (1880-1886). Educação \& Pesquisa, São Paulo, v. 26, n. 1, p. 119-133, jan./jun. 2000.

SILVA, L.O. Terras devolutas e latifúndio: efeitos da Lei de 1850. Campinas: UNICAMP, 1986. 